\title{
Vorwort zum dritten Band
}

Mit dem vorliegenden Band ist die 2. Auflage dieses Kommentars in allen Teilen abgeschlossen. Die sechs Lieferungen des III. Bandes konnten nicht ,zügig", sondern nur in größeren Zeitabständen erscheinen; im Inhaltsverzeichnis sind die Daten vermerkt. Die berufliche Belastung der beiden Bearbeiter und die wiederholte Erkrankung des einen von ihnen waren die Gründe dieser gewiß bedauerlichen Tatsache. Die Bearbeiter glaubten indes, von der Mithilfe jüngerer Kräfte, selbst mit der Folge einer langsameren Erscheinungsweise des Kommentars, Abstand nehmen zu müssen. Bei einem „Großkommentar der Praxis" entspricht eine Arbeit, die von den durch eine lange praktische Erfahrung ausgewiesenen Bearbeitern $a b$ origine persönlich geleistet ist, doch wohl am besten der Erwartung der Benutzer.

Bearbeiter und Verlag hoffen für die nächste Auflage, mit verzögernden Umständen nicht mehr rechnen zu müssen, außerdem aber hoffen sie auch, dem von Hermann Staub, dem Begründer dieses Werkes, gesetzten Ideal eines „Großen“ Kommentars einen weiteren Schritt näher zu kommen.

München, im Frühjahr 1963

v. Godin

Ratz 
